\title{
REVIEW ARTICLE Circulatory changes during gestational development of the sheep and human fetus
}

\author{
Abraham M. Rudolph ${ }^{1}$
}

BACKGROUND: Circulatory changes during gestational development of the human fetus have been considered to be similar to those noted in studies of the lamb fetus.

METHODS: Blood flow measurements derived by Doppler ultrasound and magnetic resonance imaging techniques in human fetuses at various stages of gestation have been compared with those in the lamb.

RESULTS: Combined ventricular output relative to fetal body weight does not change significantly with growth in the lamb or human. However, the proportion of cardiac output to the brain increases markedly in the human, but only slightly in the lamb fetus in the latter half of gestation. Cardiac output distribution to other organs also changes little in the lamb, but in the human, there is a marked decrease in the proportion distributed to the placenta and an increase in pulmonary flow.

CONCLUSION: The developmental changes in the distribution of combined ventricular output in the human fetus may modify the responses to circulatory disturbances, such as congenital cardiovascular malformations, dependent on gestation.

Pediatric Research (2018) 84:348-351; https://doi.org/10.1038/s41390-018-0094-9

During gestational development, growth rates may differ in various organs. Thus, the fetal-to-placental weight ratio progressively increases ${ }^{1}$. However, although organ weights relative to fetal body weight may change in the first half of gestation, the ratio of organ to body weight is constant in the last trimester ${ }^{2}$. As fetal organs mature, vascularity increases; thus, the number of arterioles in the right lung of fetal lambs increases from $7.2 \times 10^{3}$ / $\mathrm{ml}$ to $61.8 \times 10^{3} / \mathrm{ml}$ of the lung from 85 to 140 days of gestation ${ }^{3}$. The number of vessels per unit volume varies greatly in different tissues. These modifications will influence blood flows to organs, so that the distribution of the cardiac output will be altered during gestational development. The changes associated with fetal growth have been studied in fetal lambs, using radionuclidelabeled microspheres to measure blood flows ${ }^{4}$. The concepts derived from these observations have generally been applied to consideration of the cardiac output and distribution of flow in the human fetus. In recent years, the introduction of ultrasound and phase-contrast magnetic resonance imaging techniques (MRI) has provided the opportunity to study blood flow in many major vessels in the human fetus. The relationship between blood flows measured by microspheres, electromagnetic flowmeters, and Doppler ultrasonography has been examined in sheep fetuses; the descending aortic and umbilical blood flows measured by these three methods showed an excellent correlation ${ }^{5}$. Although no reports of comparison of flows measured by MRI and Doppler in fetuses could be identified, cardiac output measured by MRI and Doppler ultrasound in adult humans showed fairly good agreement ${ }^{6}$. These studies have shown that there are major differences in the blood flow patterns in the human compared with the lamb fetus and that these differences become increasingly apparent with advancing gestational age. This article reviews the differences in blood flows in the lamb and human fetus and discusses the factors that account for them. An appreciation of the dramatic gestational changes in the circulation is important in explaining the varying effects of congenital cardiovascular malformations in the human fetus.

\section{CARDIAC OUTPUT}

Postnatally, in the normal individual, it is customary to express the output of the heart as "cardiac output." This represents the volume of blood that passes sequentially through the right heart, the lungs, the left heart, and the systemic circulation. The cardiac output thus represents the volume ejected by one ventricle, and the output of each ventricle is almost identical. In view of the presence of several vascular shunts in the fetus, it has become standard practice to express the output of the heart as "combined ventricular output" (CVO); the outputs of the left and right ventricle may, however, be quite different. In the fetal lamb, the CVO is $450-500 \mathrm{ml} / \mathrm{min} / \mathrm{kg}$ fetal weight; this level is constant throughout the gestational period of 40 ( 0.4 gestation) to 140 days $(\text { term })^{4}$. In human fetuses, CVO has been measured using the Doppler technique. In one report, the CVO was constant in the fetus of gestation of 15-40 weeks with a value of about $550 \mathrm{ml} /$ $\mathrm{min} / \mathrm{kg}$ estimated fetal weight ${ }^{7}$. However, Mielke and Benda reported the values for CVO of about $450 \mathrm{ml} / \mathrm{min} / \mathrm{kg}$ in human fetuses at 13-40 weeks of gestation. In a study of blood flows measured by phase-contrast magnetic resonance imaging (PCMRI), CVO was also noted to be about $450 \mathrm{ml} / \mathrm{min} / \mathrm{kg}$ in human fetuses near term ${ }^{9}$. Thus, the CVO in relation to fetal body weight is similar in the lamb and human fetus over the latter two-thirds of gestation at about $450 \mathrm{ml} / \mathrm{min} / \mathrm{kg}$.

Although the combined output of the two ventricles is similar in the lamb and human fetus, the outputs of the left and right ventricles differ. In the lamb fetus, the right ventricle ejects about 60-65 percent and the left ventricle ejects only 35-40 percent of

${ }^{1}$ Department of Pediatrics, University of California San Francisco, San Francisco, CA, USA

Correspondence: Abraham M. Rudolph (rudolpha@sbcglobal.net)

Received: 30 January 2018 Revised: 18 May 2018 Accepted: 7 June 2018

Published online: 16 July 2018 
$\mathrm{CVO}^{10}$, with an RVO:LVO ratio of a little below 2:1. In the studies on the human fetus, all showed the ratio of RVO to LVO to be considerably lower-about 1.3:1 ${ }^{11}$. There was some inconsistency with the findings of changes during gestation. Thus, De Smedt et al. ${ }^{7}$ noted a slight decrease in the ratio from about $0.4 \mathrm{~g}$ to term, whereas Rasanen et al. ${ }^{12}$ reported an increase in RVO:LVO from about 1.2 at 0.5 gestation to 1.5 near term.

\section{ORGAN BLOOD FLOWS}

Changes in blood flow to organs and the proportions of the CVO distributed to various organs during gestational development have been studied in fetal lambs using radionuclide-labeled microspheres ${ }^{4}$. In the fetal lamb, blood flow to the carcass (muscle, skin, and bone) is about $22 \mathrm{ml} / \mathrm{min} / 100 \mathrm{~g}$ tissue weight at 0.4 gestation and it continues at this level to term. Throughout the period of 0.4 gestation to term, it is $16-20$ percent of CVO. Myocardial blood flow is about $235 \mathrm{ml} / \mathrm{kg} / 100 \mathrm{~g}$ at 0.4 gestation and about 3.8 percent of CVO and these values do not change significantly throughout gestation. Information of blood flow to these structures in the human fetus is not available. In the human fetus, blood flow to some organs, including the placenta and the lungs, have been measured by Doppler technique or PC-MRI.

\section{UMBILICAL-PLACENTAL BLOOD FLOW}

In lambs, umbilical-placental flow is about $200-220 \mathrm{ml} / \mathrm{min} / \mathrm{kg}$ of fetal weight from 60 days (0.4) gestation to 145 days (term) and it is about 45 percent of CVO at 0.4 gestation; this percentage slightly falls to about 40 percent at 140 days (term). In human fetuses, flow has been estimated from Doppler ultrasound recordings in the intra-abdominal portion of the umbilical vein, as well as in the ductus venosus. As compared with the lamb, the umbilical blood flow is considerably lower both in relation to body weight and CVO. Furthermore, it falls significantly over the gestational period of 18-40 weeks (0.5 gestation-term). Sutton et al. ${ }^{13}$ found that umbilical venous flow decreased from $134 \mathrm{ml} /$ $\mathrm{min} / \mathrm{kg}$ estimated fetal weight at 0.5 gestation to $105 \mathrm{ml} / \mathrm{min} / \mathrm{kg}$ at term. Similarly, in studies of fetuses at 18 weeks ( 0.5 gestation) to term, Kiserud et al. ${ }^{14}$ noted a decrease in umbilical flow from 32 percent CVO to 21 percent CVO after 0.8 gestation. The proportion of the umbilical venous flow that is shunted through the ductus venosus in the fetal lamb varies considerably, but the mean is about 50 percent $^{15}$ and this does not change during gestational development. In the human fetus, at 0.5 gestation, 30-40 percent of umbilical venous flow passes through the ductus venosus, but this decreases to $15-20$ percent by term ${ }^{16,17}$. Thus, in the near-term fetus, only about $15 \mathrm{ml} / \mathrm{min} / \mathrm{kg}$ estimated fetal weight traverses the ductus venosus.

\section{PULMONARY BLOOD FLOW}

In the fetal lamb, blood flow to the lungs is about $38 \mathrm{ml} / \mathrm{min} /$ $100 \mathrm{~g}$ and about 3.7 percent of CVO at 0.4 gestation; flow increases slowly to 70 (5.4 percent CVO) at 0.8 gestation and then more rapidly to $126 \mathrm{ml} / \mathrm{min} / 100 \mathrm{~g}$ ( 7.0 percent CVO) at term. In human fetuses, blood flow to the lungs has been estimated from recordings of the left and right pulmonary arteries, or by subtracting ductus arteriosus flow from the main pulmonary arterial flow. It is not possible to measure flow per unit of lung weight, but it can be expressed in relation to CVO. Pulmonary blood flow is higher relative to CVO than in the lamb. Mielke and $\mathrm{Benda}^{8}$ reported pulmonary flow as 11 percent CVO and there was no significant change with gestational age. Sutton et al. ${ }^{18}$ noted much higher flows of 20-25 percent of CVO; there was also no significant change over the second and third trimesters. However, Rasanen et al. ${ }^{12}$ observed that pulmonary flow is about 15 percent of CVO at 18 weeks of gestation and this increases to about 22 percent by 30 weeks, with no further change in later gestation.

\section{CEREBRAL BLOOD FLOW}

Brain flow relative to organ weight also increases markedly in fetal lambs from $30 \mathrm{ml} / \mathrm{min} / 100 \mathrm{~g}$ at 0.4 gestation to 101 at 0.8 gestation and to $132 \mathrm{ml} / \mathrm{min} / 100 \mathrm{~g}$ at term; as a proportion of CVO, it increases from 2.2 percent at 0.4 gestation to 3.0 percent near term. No data are available for the measurement of cerebral blood flow in human fetuses. Brain weight is about 2 percent of body weight in the fetal lamb and this relationship does not change significantly throughout gestation. In the human fetus, the brain weight is about 13 percent of body weight and this ratio also does not change during gestational development. If it is assumed that blood flow per unit weight of brain tissue in the human is similar to that in the lamb, flows and the proportion of CVO distributed to the brain can be estimated. Thus, at 0.5 gestation, with a body weight of $300 \mathrm{~g}$, a brain weight of $39 \mathrm{~g}$, and blood flow of $30 \mathrm{ml} / \mathrm{min} / 100 \mathrm{~g}$, cerebral blood flow would be $11 \mathrm{ml} / \mathrm{min}$ or 8 percent of CVO. This value is a reasonable estimate because Vimpeli et al. ${ }^{19}$ reported that 13 percent of CVO was distributed through the ascending aorta to the upper body and brain in human fetuses at $0.3-0.5$ gestation. In a term fetus with body weight of $3.5 \mathrm{~kg}$, a brain weight of $455 \mathrm{~g}$, and blood flow of $120 \mathrm{ml} / \mathrm{min} / 100 \mathrm{~g}$, cerebral blood flow would be $546 \mathrm{ml} / \mathrm{min}$ or 35 percent of CVO. This difference in the proportion of CVO distributed to the brain markedly influences the course and distribution of flow with advancing gestation, as discussed below.

\section{DISCUSSION}

Changes in the distribution of CVO

The differences between the distribution of cardiac output and organ blood flows in lamb and human fetuses, particularly in the latter part of gestation, are of great interest. The marked changes in cardiac output distribution with gestational development in the human fetus have not been adequately addressed in consideration of the influence of the effects of fetal disorders such as growth retardation and congenital cardiovascular malformations. The differences are largely related to variation in body configuration, organ size, and blood flow relative to organ weight. The changes during gestational development are very different in the human versus the lamb fetus. Thus, in the lamb, although the flow per $100 \mathrm{~g}$ of brain weight increases markedly during gestational development, since brain weight is only 2 percent of body weight throughout gestation, the cerebral flow as a percentage of CVO increases from 2 to 3 percent during the latter half of gestation (Table 1). Blood flow relative to brain weight in the human fetus probably also increases. This is supported by the observation that in human fetuses of $16-40$ weeks of gestation, there is a progressive increase in vessel density and in the percentage of blood vessel area in the germinal matrix, gray matter, and white

Table 1. Organ blood flows as percentages of combined ventricular output (CVO) in the lamb and human fetus at midterm ( 0.5 gestation) and term gestation

\begin{tabular}{|c|c|c|c|c|}
\hline \multirow[t]{2}{*}{ Blood flow } & \multicolumn{2}{|l|}{ Lamb } & \multicolumn{2}{|l|}{ Human } \\
\hline & 0.5 gestation & Term & 0.5 gestation & Term \\
\hline $\begin{array}{l}\text { Umbilical-placental } \\
\text { (\% CVO) }\end{array}$ & 45 & 40 & 35 & 20 \\
\hline Pulmonary (\% CVO) & 4 & 8 & 15 & 25 \\
\hline Cerebral (\% CVO) & 2 & 3 & 8 & 35 \\
\hline
\end{tabular}


Table 2. Gestational changes in umbilical-placental blood flow, fetal hemoglobin concentrations, oxygen content of umbilical venous (UV) blood, oxygen delivery to the fetus, glucose concentration of UV blood, and glucose delivery to the lamb and human fetus at midterm (0.5 gestation) and term gestation

\begin{tabular}{|c|c|c|c|c|}
\hline & \multicolumn{2}{|l|}{ Lamb } & \multicolumn{2}{|l|}{ Human } \\
\hline Umbilical/placental flow (\% CVO) & 45 & 40 & 35 & 20 \\
\hline Hemoglobin concentration $(\mathrm{g} / \mathrm{dl})$ & 8 & 10 & 9 & 16 \\
\hline Oxygen content UV (ml/dl) & 8.6 & 10.8 & 9.7 & 17.2 \\
\hline Oxygen delivery $(\mathrm{ml} / \mathrm{min} / \mathrm{kg})$ & 17 & 19 & 15 & 15 \\
\hline
\end{tabular}

matter ${ }^{20}$. However, because the brain weight in the human fetus is 13 percent of body weight, cerebral blood flow as a percentage of CVO increases dramatically from 8 to 35 percent of CVO through the latter half of gestation (Table 1).

Blood flow to the brain is provided by the left ventricle, so left ventricular output increases. Flow into the left atrium and ventricle is derived from pulmonary venous return and flow across the foramen ovale. In the human fetus, the proportion of CVO passing across the foramen ovale decreases in the latter half of gestation $^{12}$, whereas the percentage of CVO to the pulmonary circulation increases to provide the enhanced output of the left ventricle. To provide the increase in cerebral and pulmonary blood flows, it would be necessary for CVO to increase, or for flow to other fetal organs to be decreased.

The fetal heart is limited in its ability to increase cardiac output. As reported by Gilbert ${ }^{21}$ and by Thornburg and Morton ${ }^{22}$, volume loading of the heart in fetal lambs increases the ventricular output to a small amount as ventricular filling pressure increases, but the output plateaus with a further increase in ventricular diastolic pressure. This limit in the ability to increase output is supported by the fact that CVO relative to fetal weight does not change significantly during gestational development. So, with the limited ability to increase ventricular output, to accommodate the increase in pulmonary and cerebral flow, it is necessary to reduce flow to other organs.

In the fetal lamb, the percentage of CVO to some organs increases with advancing gestation, but, because the amounts are relatively small, the total proportion of CVO distributed to the fetal body is increased only modestly, so that umbilical-placental flow falls from 45 to 40 percent of CVO. In the human fetus, with the increase of pulmonary flow to 25 percent and of cerebral flow to 35 percent $C V O$, if umbilical-placental flow were maintained at 35 percent CVO, there would be a negligible amount available for the rest of the fetal body. Thus, in the human fetus, umbilical-placental flow falls from 35 to 20 percent CVO during the latter half of gestation (Table 1).

Pulmonary vasculature

In the fetal lamb, pulmonary blood flow is about 4 percent of CVO at 0.5 gestation and this increases to 8 percent CVO at term (Table 1). Pulmonary vascular resistance does not change significantly at 0.5 gestation with an increase in oxygen saturation of blood perfusing the lung, but the vasodilator response progressively increases to term. These pulmonary vascular responses are induced by small changes in oxygen saturation of pulmonary arterial blood ${ }^{23}$. Pulmonary vascular resistance is considerably lower in the human fetus; at 0.5 gestation, the lungs receive about 15 percent CVO and this increases to about 25 percent at term. Increased oxygenation does not affect pulmonary blood flow below 0.5 gestation, but increases flow in older fetuses ${ }^{24}$.
Oxygen and glucose supply to the fetus

The magnitude of umbilical-placental blood flow and the oxygen content and glucose concentration of umbilical venous blood determine the delivery of oxygen and glucose to the fetus. The changes with gestational development are summarized in Table 2. In the lamb fetus, umbilical blood flow as a percentage of CVO falls only slightly in the latter half of gestation. Hemoglobin concentration, based on observations in many studies, is about $8 \mathrm{~g} / \mathrm{dl}$ at 0.5 gestation and increases slightly to about $10 \mathrm{~g} / \mathrm{dl}$ at term. Thus, oxygen delivery to the fetus is estimated to be about $17 \mathrm{ml} / \mathrm{min} / \mathrm{kg}$ fetal weight at 0.5 gestation and $19 \mathrm{ml} / \mathrm{min} / \mathrm{kg}$ at term. In the human fetus, the marked decrease in umbilical blood flow from 35 percent CVO at $0.5 \mathrm{~g}$ to 20 percent at term severely compromises the delivery of oxygen. To compensate, the hemoglobin concentration markedly increases from $9 \mathrm{~g} / \mathrm{dl}$ at $0.5 \mathrm{~g}$ to $16 \mathrm{~g} / \mathrm{dl}$ at term ${ }^{25}$. Thus, the oxygen delivery is estimated to be $15 \mathrm{ml} / \mathrm{min} / \mathrm{kg}$ at $0.5 \mathrm{~g}$ and this is maintained through the latter half of gestation (Table 2).

Blood glucose concentrations are markedly different in the lamb and human fetus. In the lamb at $0.5 \mathrm{~g}$, it is about $30 \mathrm{mg} / \mathrm{dl}$ and it falls to about $20 \mathrm{mg} / \mathrm{dl}$ at term ${ }^{26}$. Thus, with the associated small decrease in the percentage of CV distributed to the placenta, there is a moderate fall in glucose delivery from $50 \mathrm{mg}$ to $36 \mathrm{mg} /$ $\mathrm{min} / \mathrm{kg}$ (Table 2). Little information is available regarding umbilical venous glucose concentration in human fetuses. Concentrations appear to be considerably higher than in the sheep at about $70 \mathrm{mg} / \mathrm{dl}$ at $0.5 \mathrm{~g}$ and $60 \mathrm{mg} / \mathrm{dl}$ at term ${ }^{27}$. Thus, with the marked fall in the umbilical venous flow as a percentage of CVO, glucose delivery per kilogram of fetal weight falls markedly from $110 \mathrm{mg} /$ $\mathrm{min} / \mathrm{kg}$ at $0.5 \mathrm{~g}$ to $54 \mathrm{mg} / \mathrm{min} / \mathrm{kg}$ at term (Table 2).

In summary, the distribution of CVO changes dramatically during gestational development in the human fetus. This is largely related to the marked increase in cerebral blood flow. Cerebral flow is derived from the left ventricle and thus left ventricular output is increased. This is provided by an increase in pulmonary blood flow. Because the fetus heart has a limited ability to increase its output, the flow to other organs has to be reduced; this is accomplished by decreasing umbilical-placental flow as a proportion of CVO. This would result in a decrease in oxygen delivery to the fetus, but hemoglobin concentration increases with advancing gestation to maintain oxygen supply. Thus, at different stages of the gestation, the changes in the distribution of CVO could influence the effects of many conditions, such as growth retardation and congenital cardiovascular malformations.

\section{ADDITIONAL INFORMATION}

Competing interests: The authors declare no competing interests.

Publisher's note: Springer Nature remains neutral with regard to jurisdictional claims in published maps and institutional affiliations. 


\section{REFERENCES}

1. Molteni, R. A., Stys, S. J. \& Battaglia, F. C. Relationship of fetal and placental weight in human beings: fetal/placental weight ratios at various gestational ages and birth weight distributions. J. Reprod. Med. 2, 327-334 (1978).

2. Mitropoulos, G., Scurry, J. \& Cussen, L. Organ weight/body weight ratios: growth rates of fetal organs in the latter half of pregnancy with a simple method for calculating mean organ weights. J. Paediatr. Child Health 28, 236-239 (1992).

3. Levin, D. L. et al. Morphological development of the pulmonary vascular bed in fetal lambs. Circulation 53, 144-151 (1976).

4. Rudolph, A. M. \& Heymann, M. A. Circulatory changes during growth in the fetal lamb. Circ. Res. 26, 289-299 (1970).

5. Schmidt, K. G., Di Tommaso, M., Silverman, M. H. \& Rudolph, A. M. Doppler echocardiographic assessment of fetal descending aortic and umbilical blood flows. Circulation 83, 1731-1737 (1991).

6. Andersson, C. et al. Phase-contrast MRI volume flow-a comparison of breath held and navigator based acquisitions. BMC Med Imaging 16, 26 (2016).

7. De Smedt, M. C., Visser, G. H. \& Meijboom, E. J. Fetal cardiac output estimated by Doppler echocardiography during mid- and late gestation. Am. J. Cardiol. 60, 338-342 (1987).

8. Mielke, G. \& Benda, N. Cardiac output and central distribution of blood flow in the human fetus. Circulation 103, 1662-1668 (2001).

9. Prsa, M. et al. Reference ranges of blood flow in the major vessels of the normal human fetal circulation at term by phase-contrast magnetic resonance imaging. Circ. Cardiovasc Imaging 7, 663-670 (2014).

10. Rudolph, A. M. \& Heymann, M. A. The circulation of the fetus in utero. Methods for studying distribution of blood flow, cardiac output and organ blood flow. Circ. Res. 21, 163-184 (1967).

11. Kenny, J. F. et al. Changes in intracardiac blood flow velocities and right and left ventricular stroke volumes with gestational age in the normal human fetus: a prospective Doppler echocardiographic study. Circulation 74, 1208-1216 (1986).

12. Rasanen, J. et al. Role of the pulmonary circulation in the distribution of human fetal cardiac output during the second half of pregnancy. Circulation 94, 1068-1073 (1996).

13. Sutton, M. S. et al. Changes in placental blood flow in the normal human fetus with gestational age. Pediatr. Res. 28, 383-387 (1990).
14. Kiserud, T. et al. Fetal cardiac output, distribution to the placenta and impact of placental compromise. Ultrasound Obstet. Gynecol. 28, 126-136 (2006).

15. Edelstone, D. I., Rudolph, A. M. \& Heymann, M. A. Liver and ductus venosus blood flows in fetal lambs in utero. Circ. Res. 42, 426-433 (1978).

16. Kiserud, T., Rasmussen, S. \& Skulstad, S. Blood flow and the degree of shunting through the ductus venosus in the human fetus. Am. J. Obstet. Gynecol. 182, 147-153 (2000).

17. Bellotti, M. et al. Role of ductus venosus in distribution of umbilical blood flow in human fetuses during the second half of pregnancy. Am. J. Physiol. Heart Circ. Physiol. 279, 256-263 (2000).

18. Sutton, M. S. et al. Assessment of changes in blood flow through the lungs and foramen ovale in the normal human fetus with gestational age: a prospective Doppler echocardiographic study. Br. Heart J. 71, 232-237 (1994).

19. Vimpeli, T., Huhtala, H. \& Wilsgaard, T. et al. Fetal aortic isthmus blood flow and the fraction of cardiac output distributed to the upper body and brain at 11-20 weeks of gestation. Ultrasound Obstet. Gynecol. 33, 538-544 (2009).

20. Ballabh, P., Braun, A. \& Nedergaard, M. Anatomic analysis of blood vessels in germinal matrix, cerebral cortex, and white matter in developing infants. Pediatr. Res. 56, 117-124 (2004).

21. Gilbert, R. D. Control of fetal cardiac output during changes in blood volume. Am. J. Physiol. 238, H80-H86 (1980).

22. Thornburg, K. L. \& Morton, M. J. Filling and arterial pressures as determinants of stroke volume in the sheep fetus. Am. J. Physiol. 246, H656-H663 (1984).

23. Lewis, A., Heymann, M. A. \& Rudolph, A. M. Gestational changes in pulmonary vascular responses in fetal lambs in utero. Circ. Res. 39, 536-541 (1976).

24. Rasanen, J., Wood, D. C. \& Debbs, R. H. et al. Reactivity of the human fetal pulmonary circulation to maternal hyperoxygenation increases during the second half of pregnancy. Circulation 97, 257-262 (1998).

25. Brown, M. S. in Developmental and Neonatal Hematology (eds Stockman, J. A. III \& Pochedly, C.) (Raven Press, New York, 1988).

26. Hay, W. W. Placental-fetal glucose exchange and fetal glucose metabolism. Trans. Am. Clin. Climatol. Assoc. 117, 321-340 (2006).

27. Taricco, E., Radaelli, T. \& Rossi, G. et al. Effects of gestational diabetes on fetal oxygen and glucose levels in vivo. BJOG 116, 1729-1735 (2009). 